\title{
Dynamic acoustic shell with diffusers in the acoustical treatment of Carolina Coronado Theatre, Almendralejo (Badajoz, Spain)
}

\section{Una concha acústica con difusores en el tratamiento acústico del teatro Carolina Coronado de Almendralejo (Badajoz, España)}

\author{
Manuel Martín-Castizo (Main Author) \\ Instituto Tecnológico de Rocas Ornamentales y Materiales de Construcción, INTROMAC. \\ Campus Universidad de Extremadura, 10071, Cáceres (Spain) \\ mmartin@intromac.com
}

Rubén Maderuelo-Sanz (Corresponding Author)

Instituto Tecnológico de Rocas Ornamentales y Materiales de Construcción, INTROMAC.

Campus Universidad de Extremadura, 10071, Cáceres (Spain)

rmaderuelo@intromac.com

\author{
Manuscript Code: 749 \\ Date of Acceptance/Reception: 01.04.2018/01.03.2016 \\ DOI: $10.7764 /$ RDLC.17.1.38
}

\begin{abstract}
Carolina Coronado Theatre was inaugurated in 1916. Its original design resembles a classical opera theatre, having a traditional horseshoe form, used throughout $19^{\text {th }}$ century. Before the renovation its volume-number of seats ratio and its reverberation time with audience, were far away from some recommended values. Its renovation was done respecting faithfully the original appearance of the hall, without changes in the raised stage, seating area or walls and only including a new concept of acoustic dynamic shell based in diffusers, above the stage, that can create different acoustical ambiences. This acoustic configuration was slightly helped by covering lateral walls with acoustic panels. The results were obtained from the simulations in the software ODEON and "in situ" measurements.
\end{abstract}

Key words: Reverberation time, room acoustics, acoustic shell, computer simulation, diffuser.

\section{Resumen}

El teatro Carolina Coronado fue inaugurado en 1916. Su diseño original se asemeja a un teatro de ópera clásico, con planta en forma de herradura, y que se utilizó durante todo el siglo XIX. Antes de su renovación, la relación volumen-número de asientos y el tiempo de reverberación con la sala ocupada, diferían bastante de los valores recomendados. Su remodelación se realizó respetando fielmente la apariencia original de la sala, sin cambios en el escenario, zona de asientos o paredes y únicamente incluyendo un nuevo concepto de concha acústica dinámica, basada en difusores, situada en la parte superior de la caja escénica, mediante la que se pueden crear diferentes ambientes acústicos en función del uso de la sala. Esta configuración acústica se ayudó ligeramente mediante la colocación de paneles acústicos en las paredes laterales. Los resultados se obtuvieron a partir de las simulaciones con el software ODEON y medidas "in situ".

Historical buildings or bridges are very important for the history and the culture of the cities and their population (González, Fernandez-Ordóñez, Conde-Salazar \& Roig, 2015). The structure of Carolina Coronado Theatre, built at the beginning of the last century, follows the concept of the "Italian-style theatre", used throughout the $19^{\text {th }}$ century. It was designed in harmony to the creative spirit of the great halls. The theatre was conceived as a great hall with majestic dimensions. The height from the ceiling to the main seating area is more than 15 metres, where the stalls were located, supported by wrought iron columns (Figure 1). The plan of the portuguese architect Coffino, which gave risen to its construction, is dated 1913, very previous to other theatres which were built at that time in Extremadura, some of which have now disappeared. Its constructors were probably influenced by the significant demographic and economic growth of the city of Almendralejo, from the second half of the $19^{\text {th }}$ century, which made possible the construction of buildings for cultural or public activities, having considerable artistic value, such as: the bull square (1834), the Carolina Coronado Theatre (1916) or the Mercantile Circle (1924). 


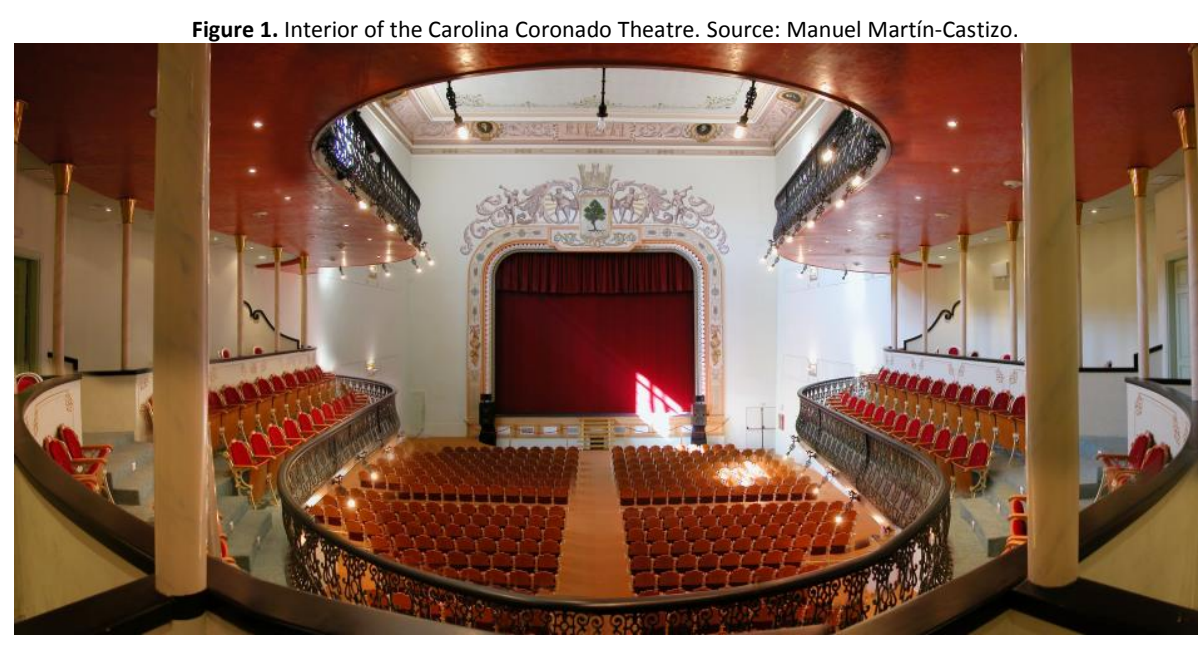

The works plan put in motion by the Government of Extremadura in 2002 included: the reconstruction of the two floors in the gallery; to recovery of the boxes that the theatre originally had, to recovery the paintings from 1916 painted by the artist Adelardo Covarsí, new floor tiles in the main seating area, etc. These works are another example of the policy of renovation and rehabilitation of the stages of this region, making it possible for it, to return to its original function as a theatre. As the building opened in 1916, the building, rehabilitated in 2004, showed deficient acoustics performance and, for this reason, the Government of Extremadura decided to correct the acoustic problems. The basic acoustic solutions for this space, used mainly for theatrical activities, are aimed for the intelligibility of the word or the level of comprehension for the oral message, being optimal at all points in the hall, and the sound level, indicative of the amplification of the hall, being sufficiently high. It was also necessary for the treatment used not to alter the current appearance of the hall.

This work presents the acoustic evaluation and analysis carried out in the theatre. Firstly an "in situ" measurement of reverberation time was made, following the requirements laid down by ISO 3382-1 (International Organization for Standardization, 2009), which refer to the modern technique of integrated impulse response for analysis of halls using pseudo-aleatory sequences, and IEC 60268-16 (International Electrotechnical Commission, 2011), which measurement procedure can be simulated in ODEON. On the basis of the results obtained, the 3-D model and its acoustic simulation were made with ODEON to give us a detailed analysis of the sound field of the hall on the basis of the acoustic parameters provided. Finally, new measurements were carried out of the acoustic conditions of the enclosure, the treatment having been completed, in order to check that the conditions were those hoped for and that the quality requirements necessary for use as a theatre are complied with.

Description of the Problem

The relation between the volume, $\mathrm{V}$, and the number of seats, $\mathrm{N}$, of a theatre must be approximately between 4 to 6 $\mathrm{m}^{3}$ by seat. Initially the $\mathrm{V} / \mathrm{N}$ ratio in the theatre was $10.84\left(\mathrm{~V}=7049 \mathrm{~m}^{3}, \mathrm{~N}=650\right)$, higher than the recommended values. Hence it can be said, given the "live" nature of the hall, that the volume excess in this space is a greatest problem, to achieve the adequate acoustic quality which this type of hall must have. This will characterise its acoustic behaviour, in such a way that the most suitable value for $\mathrm{T}_{30, \text { mid }}$, the parameter which, on a global basis, best describes this behaviour, when the hall is occupied and according to the values recommended by Cremer, Müller, \& Schultz (1982), must be between 0.91 and $1.40 \mathrm{~s}$. The reverberation time measured are excessively high, causing the sonority of the hall and, at the same time, an appreciable reduction of the intelligibility of the word and, hence, it is necessary to increase sound absorption significantly at all frequencies, without being able to reduce the volume as has been indicated. The measurements provided information about the reverberation time (RT), early decay time (EDT) and speech clarity (Definition, $\mathrm{D}_{50}$ ) while the computer simulations served to evaluate the Speech Transmission Index (STI). This last parameter, STI, was obtained with the so-called indirect method, used by ODEON, an alternative method that uses the impulse response as suggested by Schroeder (1981).

Taking into account the acoustic problem, the conservation requirements and the budget allocated for acoustic correction, three fundamental courses of action were adopted; first, an increase of sound absorption, using construction solutions formally, according to the space to be renovated; second, increasing the diffusion reflections, in terms of geometry, from those reflective planes and surfaces which are causing prejudicial reflections; and finally, to re-design the stage space, in order to facilitate early reflections towards the audience, through a great soundboard in form of an acoustic shell. 


\section{Preliminary acoustic measurements}

Measurements were made of in its original condition (previously to the intervention) in order to obtain its acoustic qualities in sufficient detail. These measurements were carried out by a laptop-based system using WinMLS 2004 software. This software acquired the data through a $1 / 2$ " microphone, type 4189 from Brüel \& Kjaer, from the output of an amplified full-duplex Sound Blaster Audigy 2 NX sound card connected to a omnidirectional source, type 4295 from Brüel \& Kjaer, placed in the centre of the stage, using swept sine signals generated by WinMLS software. The positions of the microphones are showed in the Figure 2, five in the stalls, two in the first gallery and two in the second gallery. These measurements were made in all cases with the hall and the stage completely empty. The receiver-source distance from each positions of the microphones is showed in the Table 1.

\begin{tabular}{ccccc}
\multicolumn{5}{c}{ Table 1. Coordinates and distance from each microphone position to the sound source. } \\
\hline & $\mathrm{X}$ & $\mathrm{Y}$ & $\mathrm{Z}$ & Distance $(\mathrm{m})$ \\
\hline P1 & 5.0 & 2.4 & -1.0 & 5.64 \\
P2 & 9.0 & 6.0 & -1.0 & 10.86 \\
P3 & 15.0 & 2.4 & -1.0 & 15.22 \\
P4 & 22.5 & 1.0 & -1.0 & 22.54 \\
P5 & 20.0 & 6.5 & -0.5 & 21.04 \\
P6 & 15.0 & 6.0 & 2.0 & 16.28 \\
P7 & 27.0 & 1.6 & 3.4 & 27.26 \\
P8 & 15.0 & 6.0 & 6.0 & 17.23 \\
P9 & 27.5 & 1.4 & 7.5 & 28.54 \\
\hline
\end{tabular}

Figure 2. Elevation and plant plane with the measurement points. Source: ODEON.
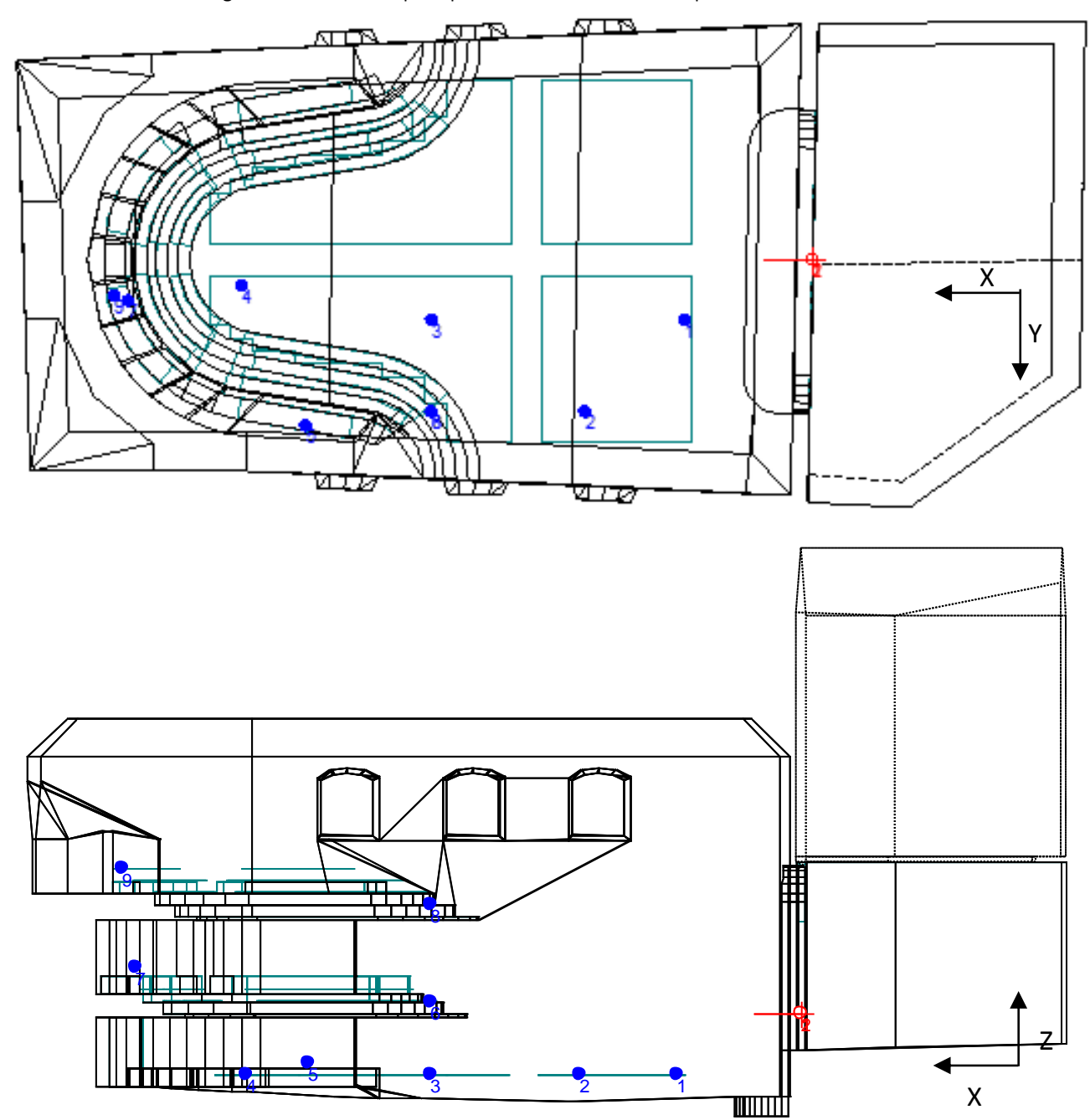
Due to its importance, we mention the average values (9 points of measurement) of the reverberation time for each one of the octave band between $125 \mathrm{~Hz}$ and $4 \mathrm{kHz}$ for the empty hall (Figure 3). The average $\mathrm{T}_{30}$ values for the occupied hall $\left(R T_{0}\right.$ ) and the optimal $R T$ values ( $R T_{\text {opt }}$ ) are also given. The $R T_{0}$ values were obtained based on the experimental measurements and the difference of the absorption coefficient $\Delta \alpha$ between full and empty seat, using the following expression: $\mathrm{RT}_{\mathrm{o}}=\mathrm{RT} /(1+4.30 . \Delta \alpha \mathrm{NRT} / \mathrm{V})$, derived from the Sabine formula, accepting that the audience area according to Beranek (1996) is $0.697 \mathrm{~N}$, where $\mathrm{N}$ is the number of seats, 650 in this case. The RT opt values were calculated following this expression: $\mathrm{RT}_{\mathrm{opt}}=k u \mathrm{~V}^{1 / 3}$ (Pérez Miñana, 1969) where $\mathrm{V}$ is the volume of the room, $k$ is depending from the frequency and $u$ from the signal used in the room.

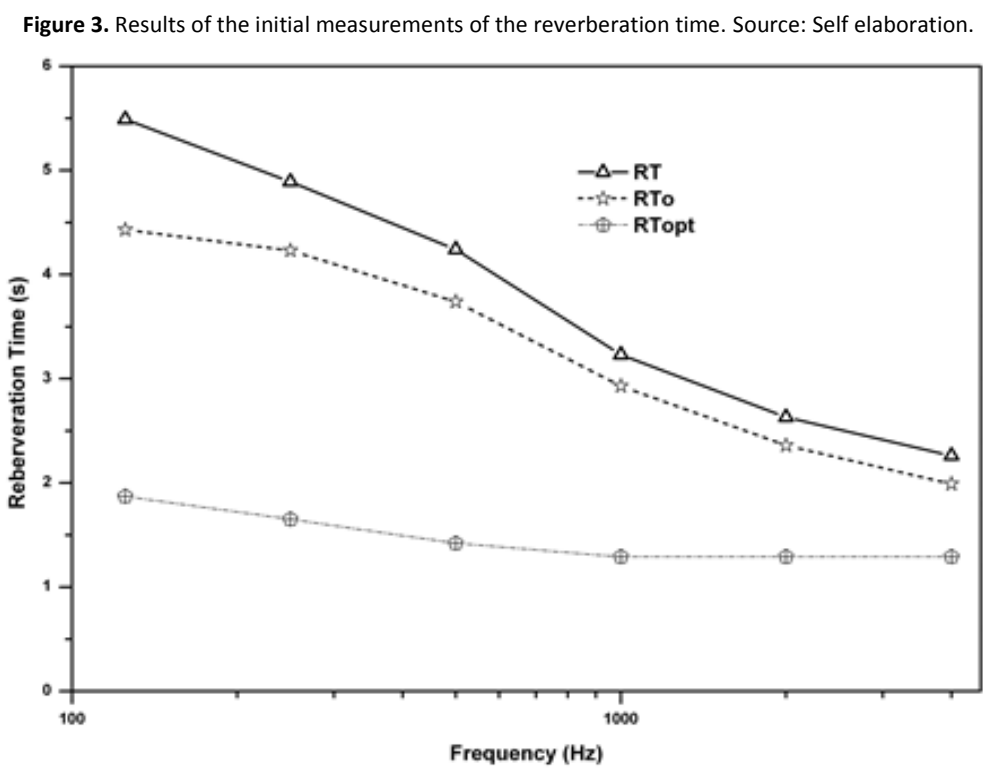

The $T_{30 \text {,mid }}$ obtained for the occupied hall is $3.33 \mathrm{~s}$. As can be seen the reverberation times recorded are excessively high, making difficult the intelligibility of the word, so it is necessary to increase absorption significantly at all frequencies. Other results found in these measurements not only confirmed the high reverberation time of the original enclosure (EDT mid of $3.21 \mathrm{~s}$, values for $\mathrm{D}_{50}$ below 0.2 for medium frequencies and C 80 "music average" of $-3.8 \mathrm{~dB}$ ), they also indicated that the STI index values were always between 0.3 and 0.4 , so it is possible to affirm that the acoustics of the theatre deserved the rating of "poor".

\section{Computer simulation}

To correct and to adapt the sound field inside the hall the acoustic simulation software ODEON 10.0 was used. A 3-D model of the theatre was created using Autocad on the basis of the graphic documentation provided by the architect responsible for the renovation. From the DXF file we obtained a final model 579 faces and 1442 corners. Some different simulations were carried out, all of them using the same basic parameters (number of rays, length of impulse response, number and position of receivers, etc.) analyzing the situation of an unoccupied hall in original state and the situation of an occupied hall with the treatments finally proposed. All the simulations used were carried out in the most unfavourable situation: an orator, without sound reinforcement, from the centre of the edge of the stage.

Two types of source were chosen: one omnidirectional to adjust the model comparing the results with the preliminary acoustic measurements, and for the obtaining of the acoustic parameters, with a gain of $31 \mathrm{~dB}$, and another "Talkraise", which has a radiation diagram similar to the human voice, for intelligibility parameters, with a level of 66.5 dBA. As in practice, STI values rarely exceed 0.8 , in most practical cases it is sufficient to establish only the NC-15 curve, as entry data to evaluate this intelligibility parameter, so the background noise measurement is not required and the STI can be calculated from any impulse response measurement.

The acoustic solutions and treatments consisted, basically, in covering the lateral surfaces with 40 mm BASWA ${ }^{\circledR}$ phon acoustic panels (classic fine finish) from the skirting board to the mouldings for the ceiling, the vertical surface of the back of the hall, located in the second gallery and all surfaces located in the upper third of the entrances and walls after the boxes in the stalls and first gallery, just above the screens separating the boxes. Table 2 shows absorption coefficients and NRC Ratings for these panels (Baswana, 2016). 


\begin{tabular}{|c|c|c|c|c|c|c|c|}
\hline Frequency $(\mathrm{Hz})$ & 125 & 250 & 500 & 1000 & 2000 & 4000 & NRC Ratinng \\
\hline Absorption coefficient & 0.31 & 0.63 & 0.98 & 0.90 & 0.87 & 0.76 & 0.85 \\
\hline
\end{tabular}

Also and as a treatment a new concept was used on the stage of acoustic shell based on RPG diffusion panels of the FORMEDFFUSOR model which by way of their dynamic create compatibility with theatrical activity and with other more usual activities, achieving different acoustic ambiences. It absorption and dispersion coefficients are showed in Acoustic GRG Products Ltd (2016). These "acoustic clouds" (Figures 4 and 5) are placed on the stage as follows: one at the back of the stage, four side clouds, two on each side occupying the gaps and nine roof clouds, with a total diffusing surfacearea of approximately $140 \mathrm{~m}^{2}$.
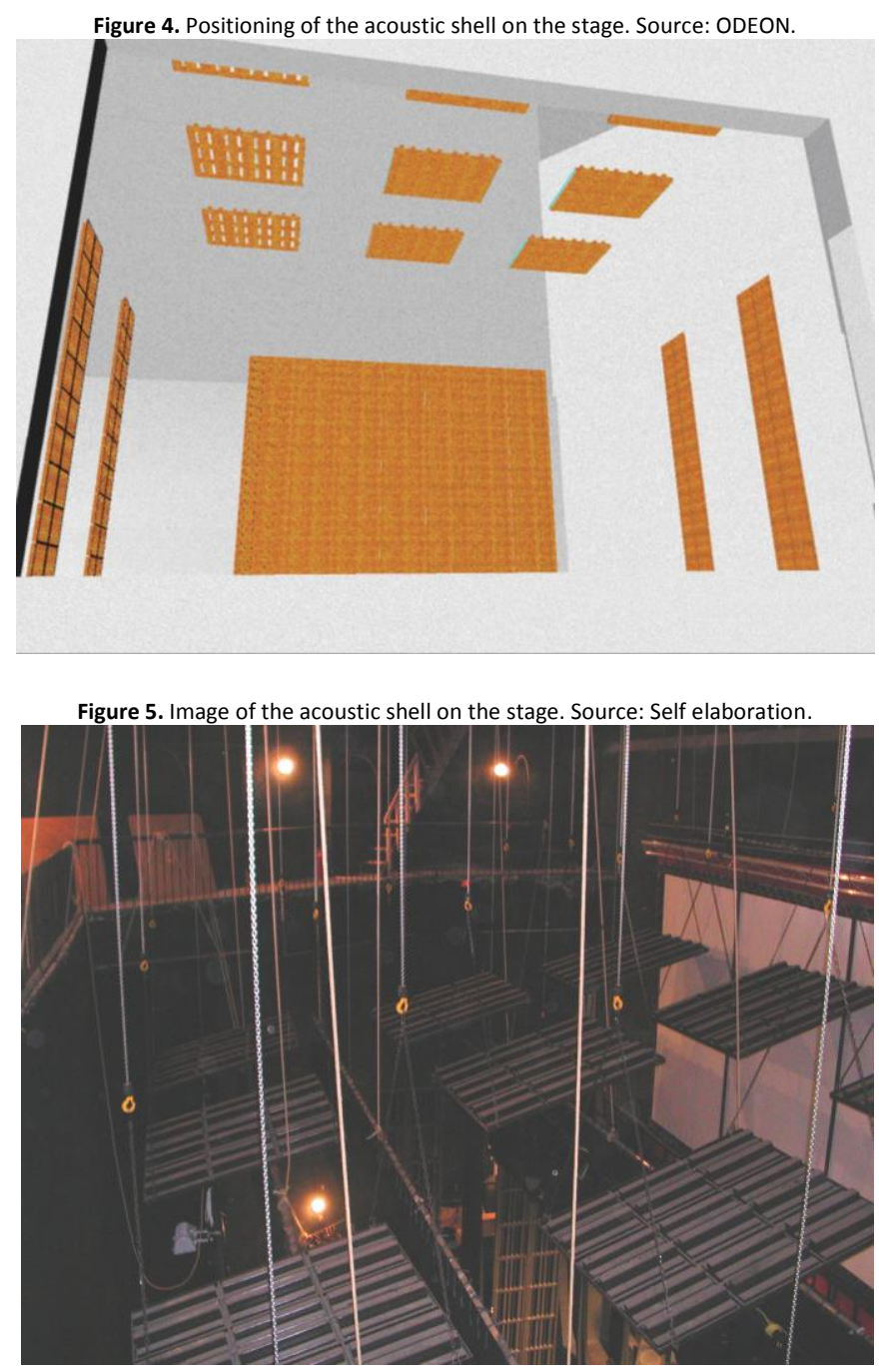

\section{Simulation results after acoustic treatments}

To keep this report brief, only the results found in the study hypotheses of extreme situations are given in Table 3.The first of these refers to the original situation of the hall without audience, and the second and third to the hall while unoccupied and occupied with the treatments described, respectively. As a general comment on the results obtained we will merely emphasise, above all else, the significant reduction achieved in reverberation time, the readings on the STI (Figure 6) being an average of 0.64 which is classified as "good", and finally, based on the echograms obtained and the path analysis carried out, stress the favourable reflections which occur thanks to the diffuser elements installed in the cork of the stage and which contribute to a uniform sound distribution in most of the audience area. Table 4 shows the STI values from each microphone position for computer simulation and final measurements. 
Table 3. Theoretical results obtained with computer simulation. Source: Self elaboration.

\begin{tabular}{|c|c|c|c|c|c|c|c|c|}
\hline Frequency & 125 & 250 & 500 & $1 \mathrm{~K}$ & $2 \mathrm{~K}$ & $4 \mathrm{~K}$ & & \\
\hline \multicolumn{9}{|c|}{ Simulation A (original situation unoccupied) } \\
\hline $\mathrm{T}_{30}(\mathrm{~s})$ & 5.31 & 4.86 & 4.10 & 3.36 & 2.93 & 1.91 & $\mathrm{~T}_{30 \text {,mid }}$ & 3.73 \\
\hline $\mathrm{C}_{80}(\mathrm{~dB})$ & -7.1 & -6.7 & -5.7 & -3.5 & -2.5 & -1.0 & $\mathrm{C}_{80}$ (music average) & -3.9 \\
\hline \multirow[t]{2}{*}{$\mathrm{D}_{50}$} & 0.12 & 0.13 & 0.16 & 0.22 & 0.26 & 0.33 & STI & 0.39 \\
\hline & & & & & & & $\% A L C o n s$ & 20.6 \\
\hline \multicolumn{9}{|c|}{ Simulation B (unoccupied) } \\
\hline $\mathrm{T}_{30}(\mathrm{~s})$ & 3.00 & 2.35 & 1.53 & 1.53 & 1.39 & 1.41 & $\mathrm{~T}_{30, \mathrm{mid}}$ & 1.53 \\
\hline $\mathrm{C}_{80}(\mathrm{~dB})$ & -3.2 & -1.9 & -0.5 & -0.2 & 1.0 & 1.0 & $\mathrm{C}_{80}$ (music average) & 0.6 \\
\hline \multirow[t]{2}{*}{$\mathrm{D}_{50}$} & 0.19 & 0.26 & 0.38 & 0.42 & 0.45 & 0.48 & STI & 0.49 \\
\hline & & & & & & & $\% A L C o n s$ & 12.0 \\
\hline \multicolumn{9}{|c|}{ Simulation C (occupied) } \\
\hline $\mathrm{T}_{30}(\mathrm{~s})$ & 2.57 & 2.12 & 1.49 & 1.47 & 1.41 & 1.30 & T30,mid & 1.48 \\
\hline $\mathrm{C}_{80}(\mathrm{~dB})$ & -2.4 & -1.3 & 0.7 & 0.7 & 1.0 & 1,4 & $\mathrm{C}_{80}$ (music average) & 0.8 \\
\hline \multirow[t]{2}{*}{$\mathrm{D}_{50}$} & 0.26 & 0.40 & 0.57 & 0.59 & 0.68 & 0.70 & STI & 0.64 \\
\hline & & & & & & & $\% A L C o n s$ & 5.3 \\
\hline
\end{tabular}

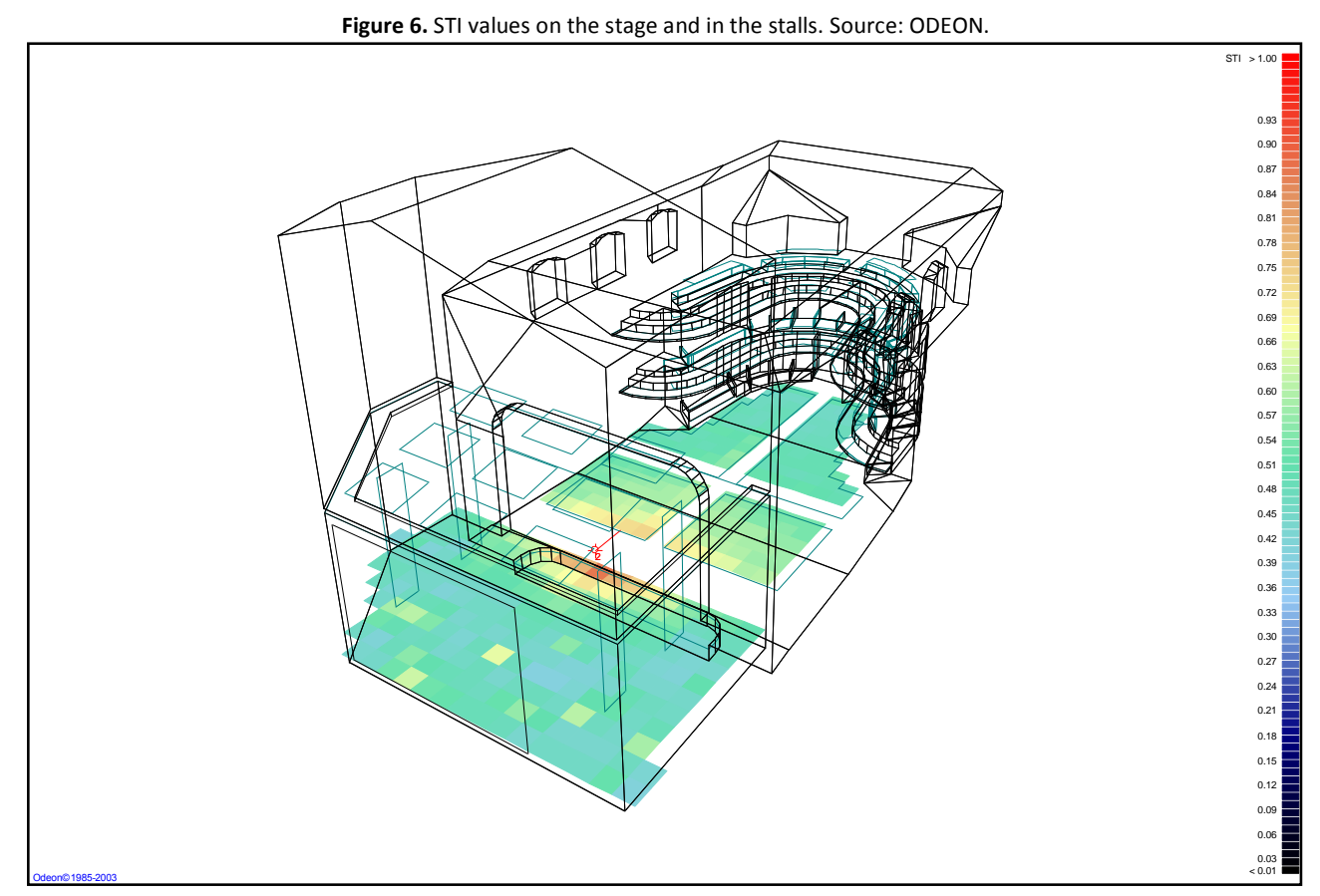

Table 4. STI values from each microphone position from computer simulation and from final measurements. Source: Self elaboration.

\begin{tabular}{ccccc}
\multicolumn{5}{c}{ STI } \\
\hline & Sim. A & Sim. B & Sim. C & Final measurements \\
\hline P1 & 0.50 & 0.55 & 0.75 & 0.62 \\
P2 & 0.39 & 0.44 & 0.68 & 0.48 \\
P3 & 0.36 & 0.47 & 0.58 & 0.50 \\
P4 & 0.38 & 0.53 & 0.64 & 0.57 \\
P5 & 0.43 & 0.52 & 0.63 & 0.55 \\
P6 & 0.35 & 0.46 & 0.59 & 0.48 \\
P7 & 0.41 & 0.49 & 0.62 & 0.55 \\
P8 & 0.35 & 0.45 & 0.59 & 0.46 \\
P9 & 0.38 & 0.46 & 0.65 & 0.50 \\
\hline & 0.39 & 0.49 & 0.64 & 0.52 \\
\hline
\end{tabular}


As we can see in the Table 4, generally, in the stalls and in the balconies, the greater the distance from the receiver to the source, the lower the value of STI is.

\section{Final acoustic measurements}

Having carried out the solutions and treatments described new measurements were made in accordance with ISO 3382 1 (International Organization for Standardization, 2009) and IEC 60268-16 (International Electrotechnical Commission, 2011) to check that acoustic behaviour was as expected and that the necessary quality requirements for use as a theatre were complied with. These measurements were carried out with the same equipment and in the same conditions as the preliminary measurements to allow comparison of the results obtained. New receiver positions were also added on the stage in order to analyse the dynamic of the acoustic shell. The results of this phase are summarised below (Table 5 and Figure 7). It can see the similarity of some results of the final acoustic measurement and the computer simulation, and the notable improvement of the parameters measured, which shows the utility of these techniques in acoustic renovation processes. According to Arau (1999), it is possible to correlate the value of $\mathrm{T}_{30 \text {, mid }}$ with the type of music that better can be played in the room. In this case, a experimental value of $T_{30, \text { mid }}=1.66 \mathrm{~s}$ is according to a Chamber music where $1.32<\mathrm{T}_{30 \text {, mid }}<1.85$.

Figure 7. Initial and final measurements of the reverberation time. Source: Self elaboration.

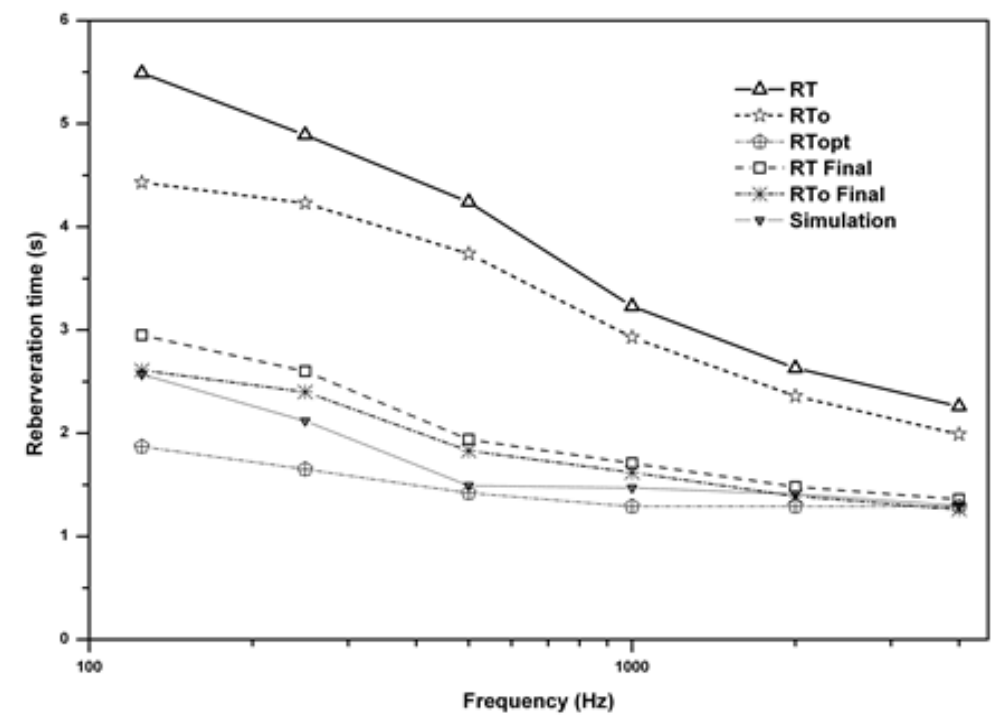

Table 5. Experimental values for unoccupied hall. Source: Self elaboration.

\begin{tabular}{lrrrrrrlr}
\hline Frequency & 125 & 250 & 500 & $1 \mathrm{~K}$ & $2 \mathrm{~K}$ & $4 \mathrm{~K}$ & \\
\hline $\mathrm{T}_{30}(\mathrm{~s})$ & 3.02 & 2.25 & 1.75 & 1.56 & 1.35 & 1.23 & $\mathrm{~T}_{30, \text { mid }}$ & 1.66 \\
$\mathrm{C}_{80}(\mathrm{~dB})$ & -3.3 & -1.6 & -0.2 & 0.4 & 1.2 & 1.7 & $\mathrm{C}_{80}$ (music average) & 0.5 \\
$\mathrm{D}_{50}$ & 0.19 & 0.26 & 0.38 & 0.37 & 0.40 & 0.40 & $\mathrm{STI}$ & 0.52 \\
& & & & & & & $\% A L C o n s$ & 10.2 \\
\hline
\end{tabular}

\section{Acoustic shell for theatrical performance}

One of the novel features of this intervention has been the use of a new concept of acoustic shell based on panels diffusing the sound over the stage, which by this dynamic makes it compatible with theatre activity and other more common uses, achieving different acoustic ambiences. Although the use of reflecting acoustic shells (Jaffe, 2005), and to a lesser extent those manufactured by way of diffuser elements (Cox \& D'Antonio, 2005), is quite widespread for use in musical concerts, the difficulty of arranging them between the stage machinery and the theatre's decoration has meant that there is practically no use of them in these stage spaces.

To evaluate the advantages of the new acoustic shell the support parameter ST1, based on the ratio between the sound energy reflected back from the room in time interval of 20-100 ms relative to the direct sound energy (including the floor reflection), being the source receiver distance $1 \mathrm{~m}$, proposed by Gade (1981), was measured on the stage in four different positions, without the shell and with the nine ceiling clouds at 7, 8 and 9 metres over the floor of the stage. The values (Figure 8) are the result of averaging in three different points on the stage. The incorporation of diffuser elements in the acoustic shell gives a substantial improvement in balance and communication between the actors, 
instruments in the case of music, due to the uniform dispersion of the energy in all directions. Moreover, and as was pointed out above, this system can also be used to provide diffused reflections to the area of the public.

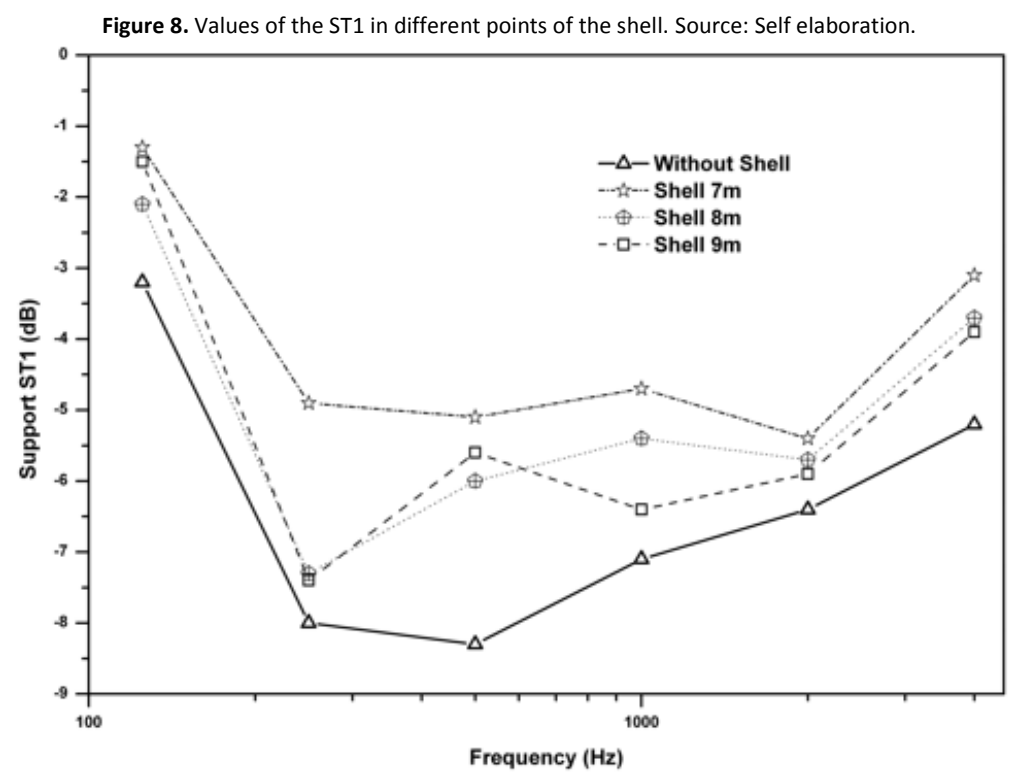

Conclusions

Room acoustical simulation software has been used to predict the main acoustic parameters of the Carolina Coronado theatre. The calculation parameters were selected by balancing the recommendations of the ODEON software.

Even though the values predicted by the software and "in situ" measurements are very similar for some of the acoustic parameters $\left(\mathrm{T}_{30}, \mathrm{~T}_{30}\right.$,mid, $\left.\mathrm{STI}\right)$ there are notable differences in certain results, especially in parameters derived from the impulse response $\mathrm{C}_{80}$ and $\mathrm{D}_{50}$ for frequencies upper $500 \mathrm{~Hz}$ and \%ALCONS. Reverberation Time and C80, obtained from in situ measurements after treatments, show that the best type of music that could be played in the room is Chamber music.

The computer simulations of the Speech Transmission Index (STI) produced results exceeding 0.45 for most of the seating area and for simulation B, C and "in situ" measurements. These results reflect speech intelligibility that is at least satisfactory, according to the recommendation of the EN 60268-16 standard.

To conclude, it should merely be indicated that our positive general evaluation of the results obtained from the work on the Carolina Coronado Theatre, which can be classed as good or even excellent, has been confirmed by the favourable view of actors, musicians and the public in the months since the work was carried out.

\section{References}

Acoustic GRG Products Ltd. (2016). Formedffusor Acoustic Data. Date accessed 11/02/2016. Available online at: http://www.rpgeurope.com/products/product/formedffusoracousticdata.html

Arau, H. (1999). ABC de la Acústica Arquitectónica. Barcelona, CEAC ed.

Baswana. (2016). Baswa Acoustic. Technical Data. Date accessed 18/02/2016. Available online at: https://www.baswana.com/technical-data

Beranek, L.L. (1996). Audience and chair Absorption in Large Halls. Journal of the Acoustical Society of America, 45, 13-19.

Cox, T.J. \& D’Antonio, P. (2005). Acoustic Absorbers and Diffusers. Theory, Design and Application (1 $1^{\text {st }}$ ed.). New York, Taylor \& Francis.

Cremer, L., Müller, H.A. \& Schultz, T.J. (1982). Principles and applications of room acoustics (1 ${ }^{\text {st }}$ ed.). London, Applied Science Publishers.

International Electrotechnical Commission. (2011). IEC 60268-16: Sound system equipment - Part 16: Objective rating of speech intelligibility by speech transmission index ( $4^{\text {th }}$ ed.). Geneva, Switzerland.

International Organization for Standardization. (2009). ISO 3382-1: Acoustics - measurement of room acoustic parameters - Part 1: Performance spaces. Geneva, Switzerland.

Jaffe, C. (2005). Innovative approaches to the design of symphony halls. Acoustic Science Technology, 26, 240-243.

Gade, A.C. (1981). Musicians ideas about room acoustic quality (Technical Report, no 31). University of Denmark. 
González, R., Fernandez-Ordóñez, B., Conde-Salazar, J.M. \& Roig, S. (2015) Rehabilitation of Historic Masonry Bridges: Lessons Learned from a Medieval Bridge in Northeast Spain. Revista de la Construcción, 14(2), 9-13.

Pérez Miñana, J. (1969). Compendio práctico de acústica aplicada. Barcelona, Labor Ed.

Schroeder, M.R. (1981). Modulation Transfer Functions: Definition and Measurement. Acustica, 49, $179-182$. 